\title{
Efficient chemical synthesis of heparin-like octa-, deca- and dodecasaccharides and inhibition of FGF2- and VEGF 165 -mediated endothelial cell functions
}

\author{
Gavin J. Miller, ${ }^{a \dagger}$ Steen U. Hansen, ${ }^{a \S}$ Graham Rushton, ${ }^{b \uparrow}$ Claire Cole, ${ }^{b \uparrow}$ Egle Avizienyte, ${ }^{b \uparrow}$ Gordon C. \\ Jayson $^{b}$ and John M. Gardiner ${ }^{a *}$
}

\author{
Received (in $X X X, X X X) X$ th $X X X X X X X X X 20 X X$, Accepted Xth $X X X X X X X X X 20 X X$ \\ DOI: 10.1039/b000000x
}

\begin{abstract}
A concise chemical synthesis of a series of structurallydefined heparin-like oligosaccharides is described. This work ${ }_{10}$ provides an efficient entry to octa-, deca-, and dodecasaccharides, including the first synthesis of (GICNS6SIdoA2S $)_{5}$ and (GlcNS6S-IdoA2S) $)_{6}$. Evaluation of the in vitro activity of these species against FGF2- and VEGF $_{165}$ dependent endothelial cell proliferation and migration 15 establishes that octa- and decasaccharides are more potent in targeting FGF2-induced effects, where cell migration is affected more significantly than proliferation. These structure-activity relationships exemplify the significance of 6-O-sulfation in regulating the activity of angiogenic growth 20 factors.
\end{abstract}

Heparin and heparan sulphate (H/HS) are highly-charged, ubiquitous, naturally-occurring glycosaminoglycans (GAGs) which are involved in regulating a wide range of biologically 25 important cellular signalling events that control a variety of biological functions, including angiogenesis. ${ }^{1}$ Amongst these, angiogenic signalling pathways that control angiogenesis are regulated by pro-angiogenic and anti-angiogenic cytokines, many of which depend on $\mathrm{H} / \mathrm{HS}$ for their biological activity.

30 Fibroblast Growth Factor 2 (FGF2) and Vascular Endothelial Growth Factor $165\left(\mathrm{VEGF}_{165}\right)$ are potent pro-angiogenic cytokines which require HS to bind and activate their respective receptors. ${ }^{2 \mathrm{a}, \mathrm{b}}$ We have previously demonstrated the relevance of the H/HS-cytokine axis to human cancer, ${ }^{2 \mathrm{c}-\mathrm{h}}$ through investigation 35 of size fractionated heparin-like oligosaccharides as putative competitive inhibitors of $\mathrm{H} / \mathrm{HS}$ function in vitro ${ }^{2 \mathrm{a}, \mathrm{i}}$ and in vivo, demonstrating the potency of octa- and deca-saccharides.

There is considerable interest in developing synthetic, structurally-defined H/HS sequences as tools to further probe

40 these angiogenic signalling pathways and for other structural interaction studies. Efficient synthetic routes, as well as access to a diversity of functionality, are essential to provide such agents to interrogate a range of biological targets and also with relation to potentially developing new anti-angiogenic therapies. ${ }^{3}$

A number of reports concerning the construction of various $\mathrm{H} / \mathrm{HS}$ architectures are known and address variation of sequence length and sulfation pattern. ${ }^{4}$ The majority of these target the $(\mathrm{IS})_{\mathrm{n}}$ repeating sequence, ${ }^{5}$ with disaccharide-based strategies typically introducing the S-I anomeric linkage or employing 50 iditol-based rather than iduronate donors. Noteworthy also are recent approaches utilising chemoenzymatic methodologies ${ }^{6}$ and efforts towards sequences containing mixed (GS/IS) oligomers. $^{7}$
Herein we report the first example of the total synthesis of structurally defined $(\mathrm{SI})_{5}$ deca- and $(\mathrm{SI})_{6}$ dodecasaccharides 27 5 and 28 (Figure 1) and in vitro evaluation of their ability to modulate FGF2- and $\mathrm{VEGF}_{165}$-dependent endothelial cell functions.

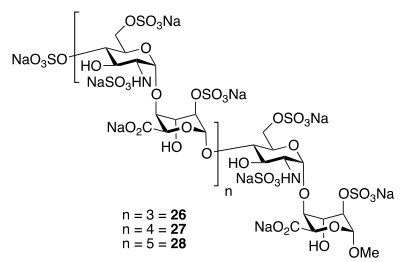

Figure 1. Synthetic heparin-like [GlcNS6S-IdoA2S $]_{\mathrm{n}}$ oligosaccharides 26-28. 60

The synthesis of these novel deca- and dodecassaccharides compliments the synthesis of the alternative dodecasaccharide sequence (IS) $)_{6}$ reported by the Bonnaffé group ${ }^{1 \mathrm{~d}}$ and an (SI) octasaccharide, similar to 26, reported by Martin-Lomas' group. ${ }^{4 \mathrm{~d}}$ ${ }_{65}$ Furthermore, our optimized approach provides rapid iterative access to multi-hundred mg quantities of octasaccharide $\mathbf{1 5}$, scalability which is pivotal to further elongations up to and including novel dodecasaccharide 19. The work was underpinned by developing a reliable $2+(2)_{n}$ disaccharide iteration strategy for 70 oligosaccharide chain elongation using stable thioglycoside iduronate donors, illustrated generically in Figure 2.

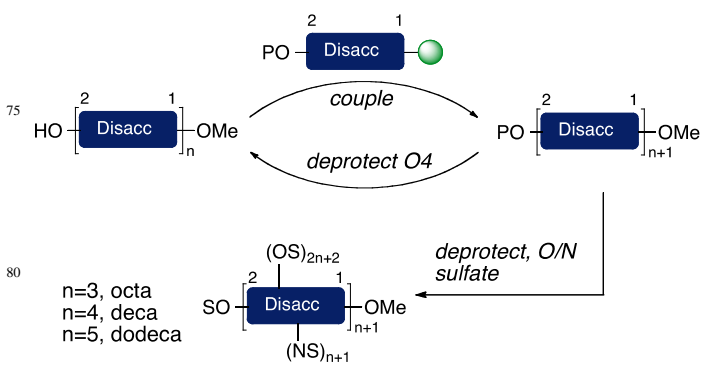

Figure 2. Iterative homologation from disaccharide level through to 8-, 8510 - and 12-mers, followed by deprotections/sulfations to access heparinlike oligosaccharides. 
This efficient synthesis utilizes only two disaccharide building blocks, 9 and 10, proceeding with very effective control over introduction of the pivotal $\alpha-1,4$, I-S linking stereochemistry with yields reliably averaging $75 \%$ for each successive round of (25 step) homologation.

To provide the requisite reducing-end cap monosaccharide $\mathbf{6}$ required to prepare the key initial disaccharide $\mathbf{9}$, we further exploited our diastereomerically pure cyanohydrin derivative $\mathbf{1}^{8}$ We have previously shown the conversion of $\mathbf{1}$ into thioglycoside 10 iduronates of type 2 (Scheme 1) and their use as effective glycosyl acceptors to access $\mathrm{H} / \mathrm{HS}$ disaccharide building blocks (including donor 10). Whilst that elaboration relied on an initial conversion of $\mathbf{1}$ via intermediary L-iduronamide derivatives, here we report that alternative Pinner type conditions convert $\mathbf{1}$ 15 directly into methyl glycosides of the iduronate methyl ester in $77 \%$ yield. Whilst this afforded the expected mixture of pyranoside and furanoside diols, subsequent acetylation furnished $\mathbf{3}$ and $\mathbf{4}$ in high yield (93\%) and allowed ready separation of these pyranoside and furanoside isomers, thus facilitating provision of $20 \mathbf{5}$ through deacetylation of $\mathbf{3}$ in $89 \%$ yield (Scheme 1).

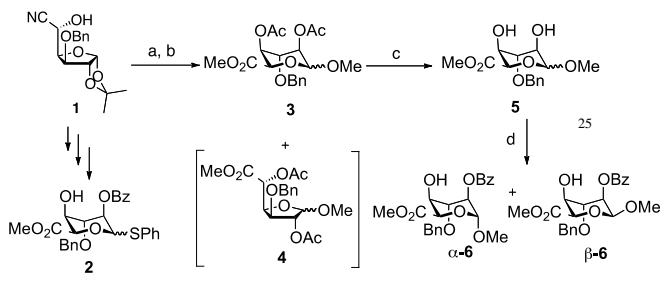

Scheme 1. L-iduronate methyl ester acceptors. (a) $\mathrm{AcCl}, \mathrm{MeOH}, 77 \%$ (b) $\mathrm{Ac}_{2} \mathrm{O}$, Pyridine, DCM, $53 \%$ for 3, $40 \%$ for 4 (c) $\mathrm{NaOMe}, \mathrm{MeOH}, 89 \%$ 30 (d) ${ }^{\mathrm{n}} \mathrm{Bu}_{2} \mathrm{SnO}, \mathrm{MeOH}$ then $\mathrm{BzCl}$, dioxane, $70 \%$ (44\% for $\boldsymbol{\alpha - 6}, 26 \%$ for $\boldsymbol{\beta}$ 6).

Following regioselective C-2 acylation of $\mathbf{5}$ using stannaneacetal chemistry, ${ }^{4 \mathrm{~g}}$ chromatographic separation afforded $\boldsymbol{\alpha}-\mathbf{6}$ and $\boldsymbol{\beta}-6$ in $70 \%$ overall yield. This route provides a new and scalable 35 entry (13.1 g of $\mathbf{5}$ prepared) into iduronate acceptors of this type, ${ }^{9}$ utilizing simple hydrolysis and acylation processes and is available in only four steps from cyanohydrin $\mathbf{1}$ (which we have shown to be available on $\mathrm{Kg}$ scale) and only eight steps (34\% overall yield) from commercially available diacetone-D-glucose.

40 Glycosylation of $\alpha-6$ was then effected using glucosaminederived trichloroacetimidate donor $\mathbf{7}^{8 \mathrm{a}, \mathrm{c}}$ under standard conditions, giving novel disaccharide $\mathbf{8}$ in $78 \%$ yield (Scheme 2). The $\alpha$-selectivity of this glycosylation was confirmed as $>95 \%$ by ${ }^{1} \mathrm{H}$ NMR analysis (GlcN $J_{1,2}=3.7 \mathrm{~Hz}$ for 8 ).

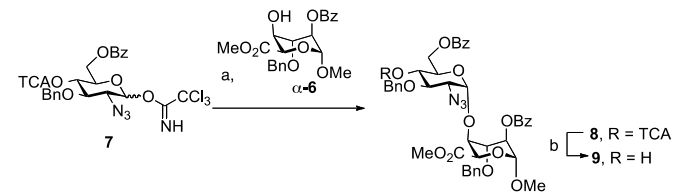

Scheme 2. Disaccharide acceptor synthesis (a) TMSOTf, DCM, 78\% (b) $\mathrm{MeOH}$, Pyridine, $95 \%$, TCA $=\mathrm{C}(\mathrm{O}) \mathrm{CCl}_{3}$.

55 Facile removal of the 4-O-TCA group from 8 using mildly basic conditions provided acceptor 9 in $95 \%$ yield. This novel disaccharide then served as the pivotal reducing terminal for iteration towards longer oligosaccharide sequences.

With effective access to 9 , our iterative $2+(2)_{\mathrm{n}}$ process constituted removal of the glucosamine-4-O-TCA from each new intermediate oligosaccharide followed by coupling with disaccharide donor unit $\mathbf{1 0}$ in each iterative cycle so that the synthesis only needed to address the introduction of I-S linkages.

Hence, coupling of $\mathbf{9}$ with $\mathbf{1 0}$ furnished tetrasaccharide $\mathbf{1 1}$ in ${ }_{65} 66 \%$ yield (Scheme 3 ) and removal of the 4-O-TCA protecting group from 11 then gave 12 in excellent yield $(91 \%)$, ready for further elongation. Continuation of this iterative glycosylation sequence was then successfully applied through two further cycles, homologating tetrasaccharide $\mathbf{1 2}$ into octasaccharide $\mathbf{1 5}$ 70 (Scheme 3) with good yields and selectivity for each glycosylation step and consistently over $85 \%$ yield for $4-O$-TCA deprotection. Our multi-gram access to the disaccharide building blocks, combined with this efficient homologation sequence, meant this methodology was effective for batch synthesis of $75>800 \mathrm{mg}$ quantities of octasaccharide $\mathbf{1 5}$. This provides an impressive 5 step route from disaccharide $\mathbf{9}$ to protected octasaccharide $\mathbf{1 5}$ in $19 \%$ overall yield and compares well to previous work delivering the closest related octasaccharide in $12 \%$ yield (7 steps). ${ }^{4 \mathrm{~d}}$

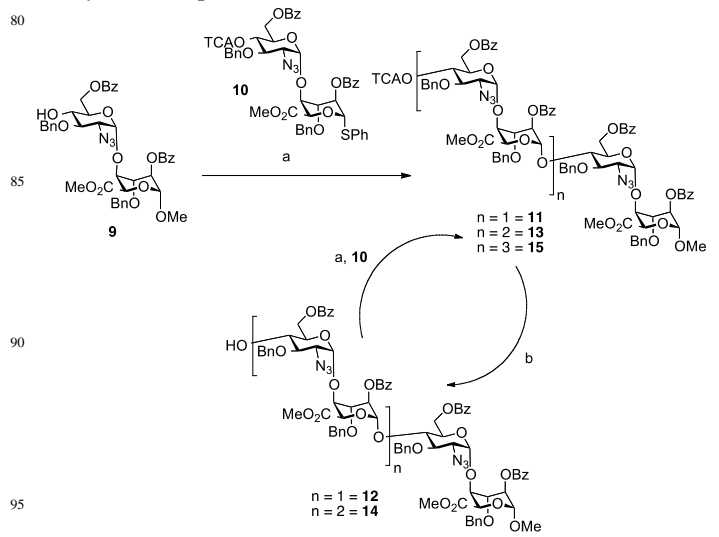

Scheme 3. Iteration to protected heparin-like octasaccharide. (a) NIS, AgOTf, DCM; 11 (66\%), 13 (57\%), 15 (64\%) (b) MeOH, Pyridine; 12 $(91 \%), 14(86 \%)$.

Octasaccharide $\mathbf{1 5}$ was then further elaborated to afford novel deca and dodecasaccharides $\mathbf{1 7}$ and $\mathbf{1 9}$ using the same iteration process (Scheme 4), with acceptor octasaccharide $\mathbf{1 6}$ elaborated into the novel dodecasaccharide 19 in $40 \%$ overall yield.

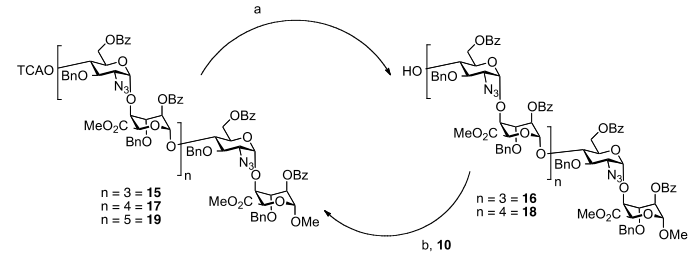

115 Scheme 4. Iteration to longer heparin-like-oligosaccharides. (a) MeOH, Pyridine; 16 (89\%), 18 (91\%) (b) NIS, AgOTf, DCM; 17 (57\%), $19(79 \%)$. 
This oligosaccharide iteration proved extremely reliable and each round of glycosylation/deprotection could be completed in under $24 \mathrm{~h}$. This demonstrates an efficient capability to more 5 readily access a range of heparin-like oligosaccharides on a scale not accessible by other means and with the potential for incorporation of disaccharides with specific sulphation patterns.

The fully protected octa-, deca- and dodecasaccharides 15,17 and 19 were then elaborated into the target species via a four-step 10 deprotection and $\mathrm{N} / \mathrm{O}$-sulfation sequence (Scheme 5).

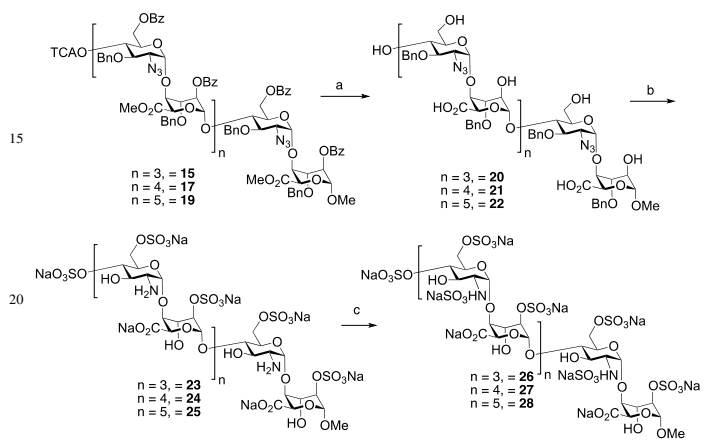

25 Scheme 5. Deprotection and sulfation of octa-, deca- and dodecasaccharides. (a) $\mathrm{LiOH}, \mathrm{THF} / \mathrm{MeOH} / \mathrm{H}_{2} \mathrm{O} ; 20$ (89\%), 21 (90\%), 22 (68\%). (b) $\mathrm{Py}_{2} \mathrm{SO}_{3}$ complex, pyridine or $\mathrm{SO}_{3} \cdot \mathrm{NMe}_{3}, \mathrm{DMF}, \mu \mathrm{W}$ then $\mathrm{H}_{2}$, $\mathrm{Pd}(\mathrm{OH})_{2} / \mathrm{C}, \mathrm{MeOH} / \mathrm{THF} / \mathrm{H}_{2} \mathrm{O} ; 23$ (75\%, 2 steps), 24 (87\%, 2 steps), 25 (71\%, 2 steps). (c) $\mathrm{Py} . \mathrm{SO}_{3}$ complex, $\mathrm{NaHCO}_{3}, \mathrm{H}_{2} \mathrm{O} ; 26$ (78\%), 27 (73\%), $3028(82 \%)$.

Firstly, ester saponification released the free carboxylic acids 20-22 and subsequent exhaustive $O$-sulfation was then effected using either Py. $\mathrm{SO}_{3}$ complex in pyridine at $50^{\circ} \mathrm{C}$ (for 20 ) or by 35 using $\mathrm{Me}_{3} \mathrm{~N}_{2} \mathrm{SO}_{3}$ under microwave conditions ${ }^{10}$ (for 21 and 22). Utilisation of microwave irradiation for this step saw a significant reduction in reaction time $(1.5 \mathrm{~h} v s 18 \mathrm{~h})$ and better overall yields. $O$-sulfation was followed by hydrogenation to remove the benzyl protecting groups and reduce the azides to furnish 23-25 in good 40 yields over the two steps. A final step $N$-sulfation of the glucosamine $\mathrm{NH}_{2}$ residues was effected using $\mathrm{Py} . \mathrm{SO}_{3}$ complex in $\mathrm{H}_{2} \mathrm{O}$ to provide 8-, 10- and 12-mer heparin-like oligosaccharides 26-28.

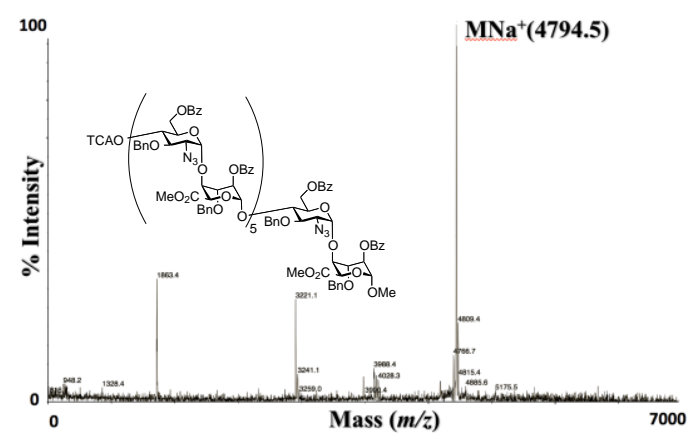

Figure 3. MALDI MS of dodecasaccharide $19\left(\mathrm{MNa}^{+}\right.$shown $)$
Protected and partially/fully-deprotected oligosaccharides of this nature present analytical challenges. In this series, high field NMR $(800 \mathrm{MHz})$ of the fully protected octa-, deca- and dodecasaccharides $(\mathbf{1 5}, \mathbf{1 7}$, and 19), provided assignment of the 50 diagnostic anomeric signals and constituent disaccharide repeating units, whilst MS analysis using MALDI techniques, proved very reliable (see Figure 3 for analysis of dodecamer 19).

Optimum analysis of oligosaccharides 23-28 required negative mode ESI-MS on samples that had undergone a carboxylic and 55 sulfonic acid counter-ion salt switch (from $\mathrm{Na}^{+}$to $\mathrm{NH}_{4}^{+}$) prior to analysis. This produced significantly less complicated spectra compared to those seen with the common $\mathrm{Na}^{+}$counterion. ${ }^{11}$

Characterization of final oligosaccharide length and homogeneity was supported by $800 \mathrm{MHz}$ NMR analyses and 60 PAGE analysis for synthetic compounds 26-28 (Figure 4), compared to heparin digest oligosaccharides of known length (Iduron). Thus, PAGE runs comparing octa-, deca- and dodecasaccharides from biological digests with synthetic 26-28 and showed good correlations.

65

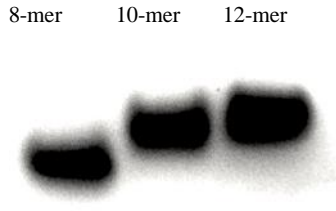

heparin digests

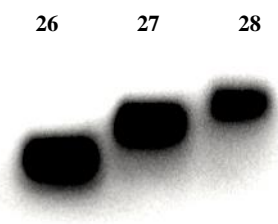

synthetic oligosaccharides
Figure 4. Azure A stained PAGE analysis of $\mathbf{2 6}$ (8-mer), 27 (10-mer) and 28 (12-mer) vs heparin digest 8-, 10- and 12-mer comparisons (4 $\mu \mathrm{g}$ 70 loading) ${ }^{\dagger}$

We previously reported that FGF2- and $\mathrm{VEGF}_{165}$-mediated signalling pathways and endothelial cell functions are inhibited by a series of lower-sulphated synthetic $(\mathrm{S} 0 \mathrm{I} 2)_{\mathrm{n}} \quad(\mathrm{n} \leq 6)$ HS oligosaccharides. ${ }^{2 \mathrm{a}}$ The most potent inhibition was achieved with 75 longer oligosaccharide sequences and $N$-sulfation of glucosamine residues was essential for activity.

We thus used FGF2- and VEGF $_{165}$-dependent endothelial cell proliferation and migration in vitro assays to evaluate whether introducing per-6- $O$-sulfation into $(\mathrm{SI})_{\mathrm{n}}$ sequences altered the 80 potential to inhibit FGF2- and $\mathrm{VEGF}_{165}$-dependent endothelial cell functions. (Fig. 5 and 6).

The proliferation results show that oligosaccharides $\mathbf{2 6}$ and $\mathbf{2 7}$ inhibit FGF2, whilst dodecasaccharide $\mathbf{2 8}$ supports the activity of FGF2 (Fig. 5); findings that are in keeping with our previous in 85 vivo study of size-fractionated 6-O-sulfated heparin oligosaccharides. ${ }^{2 \mathrm{j}}$ Moreover, this contrasts dramatically with the effect of our previously-reported synthetic [GlcNS-IdoA2S $]_{6}$ OMe dodecasaccharide, where FGF2-mediated cell proliferation was inhibited by $85 \%$. Access to the new synthetic 6 - $O$-sulfated 90 dodecasaccharide $\mathbf{2 8}$ thus enables proof of a key structurefunction switch in which $\mathbf{2 8}$ supports FGF-mediated proliferation, whilst its direct 6-O-desulfated synthetic analogue is very substantively inhibitory. 


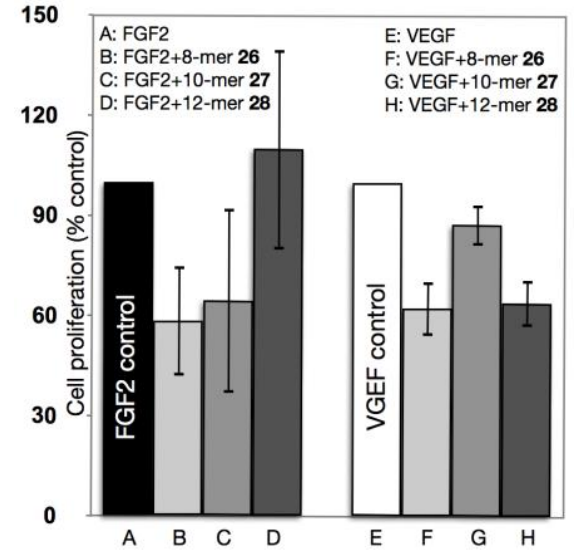

Figure 5. In vitro endothelial cell proliferation data for 26-28. Oligosaccharides 26-28 affect FGF2- and VEGF $_{165}$-induced human umbilical vein endothelial cell (HUVEC) proliferation. HUVECs were 5 maintained in endothelial cell growth media without supplements containing $1 \%$ fetal bovine serum (FBS) for six hours before adding FGF2 and $\mathrm{VEGF}_{165}$ at $5 \mathrm{ng} / \mathrm{ml}$ and $2.5 \mathrm{ng} / \mathrm{ml}$ concentration, respectively. HUVECs were cultured with the growth factors in the presence or absence of oligosaccharides $(50 \mu \mathrm{g} / \mathrm{ml})$ for 96 hours. Cell proliferation 10 was evaluated using sulforhodamine $\mathrm{B}$ assay. FGF2- and $\mathrm{VEGF}_{165^{-}}$ induced HUVEC proliferation in the absence of oligosaccharides is expressed as $100 \%$. Results are shown as mean \pm SEM.

All three oligosaccharides 26-28 inhibited FGF2-mediated 15 endothelial cell migration by 45-70\% (Figure 6). However, our previously-reported synthetic [GlcNS-IdoA2S $]_{6}-\mathrm{OMe}$ dodecasaccharide completely inhibited FGF2-mediated cell migration. This also provides another significant advancement in proof of the very different effects of sulfation within such 20 synthetic oligosaccharides.

In $\mathrm{VEGF}_{165}$-mediated cell proliferation and migration assays (Figures 5 and 6) the activities of the 8-mer (26) and 12-mer (28) were almost identical whereas the 10-mer (27), whilst having little effect on proliferation (Fig 2a), was significantly more 25 effective, inhibiting cell migration by $70 \%$. Notably, this is comparable in effect to the inhibition of VEGF-mediated migration by our synthetic 6-O-desulfated [GlcNS-IdoA2S $]_{6}$ OMe dodecasaccharide. ${ }^{2 a}$ This provides an interesting contrast between the relationship of oligosaccharide length and sulfation 30 levels in inhibiting VEGF-mediated processes.

Overall, these results, when compared with our prior biological inhibition data for the lesser-sulphated synthetic analogue series, indicate that the number and specific positions of sulphate residues in HS-related oligosaccharides have a 35 significant role in affecting different FGF2- and $\mathrm{VEGF}_{165^{-}}$ mediated processes. The lower inhibitory activity of the fully-6$O$-sulphated synthetic series 26-28 (compared with the de-6- $O$ sulphated series) against FGF2- and $\mathrm{VEGF}_{165}$-mediated endothelial cell functions, particularly exemplified by the very

40 different effects of the dodecasaccharides on FGF2-mediated proliferation and migration, could be due to the closer structural analogy to native HS S-domains, where such sequences are involved in the activation of growth factors and growth factor receptors on endothelial cells and are detected in tumour 45 endothelium. ${ }^{2 \mathrm{f}-\mathrm{h}, 12}$

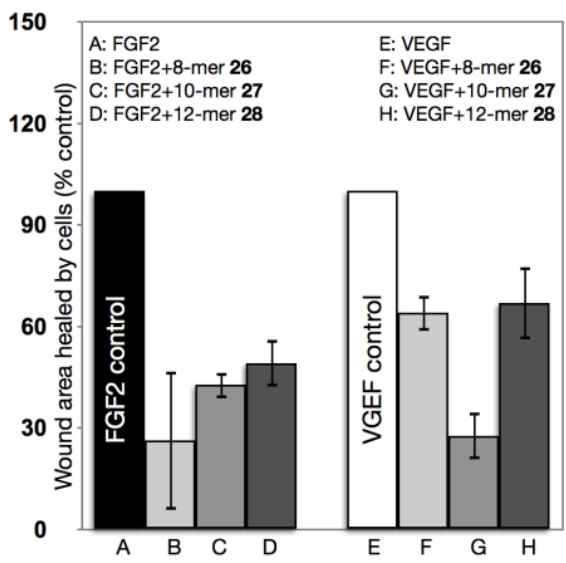

Figure 6. Inhibition of FGF2- and $\mathrm{VEGF}_{165}$-induced HUVEC migration. HUVECs were seeded to form confluent monolayers that were 50 maintained in endothelial cell growth media without supplements containing 2\% FBS for 24 hours. Following serum-starvation monolayers were wounded and FGF2 or VEGF $_{165}$ with or without oligosaccharides $(50 \mu \mathrm{g} / \mathrm{ml})$ were added at $5 \mathrm{ng} / \mathrm{ml}$ and $2.5 \mathrm{ng} / \mathrm{ml}$ concentration, respectively, for 24 hours. The images of unpopulated areas were 55 analysed using MetaMorph image analysis software by measuring unpopulated area at 0 and 24 hours. Cell advancement area was derived for each treatment. The control treatment with FGF2 or VEGF 165 alone is presented as $100 \%$. Results are expressed as mean \pm SEM

\section{${ }_{60}$ Conclusions}

In summary we have demonstrated an efficient $2+(2)_{n}$ iduronate donor-disaccharide-based synthesis of heparin-like oligosaccharides, delivering the first examples of deca- and dodecasaccharides with the (SI) repeat unit. The protected 65 octasaccharide precursor can be prepared on up to multi-hundredmg scales and demonstrates a robust entry to access essential, structurally-defined [GlcNS6S-IdoA2S $]_{n}$ oligosaccharides. Evaluation of these compounds in in vitro endothelial cell-based assays has enabled us to highlight the critical role that the 70 glucosamine-6- $O$-sulphate residue plays in the regulation of cytokine activity by HS and provides important structure-activity information, which will prove insightful in the future design and development of new anti-angiogenic synthetic HS agents.

\section{Notes and References}

The CRUK [C2075/A9106] and MRC [G0601746 and G902173] are thanked for project grant funding. EPSRC for NMR instrumentation (GR/L52246) and the EPSRC National Mass 80 Spectrometry Service, Swansea are also thanked for mass spectroscopic analyses. 


\section{Author contributions}

†Iduronate development, oligosaccharide synthesis and wrote manuscript (GJM), ${ }^{\S}$ iduronate development (SUH), "biological evaluations (EA, CC, GR), overall project planning, supervision 5 and writing (JMG and GJ).

${ }^{a}$ Manchester Institute of Biotechnology, School of Chemistry, Faculty of Engineering and Physical Sciences, The University of Manchester, 131 Princess Street, Manchester M1 7DN, UK. Tel: +44 (0)161 306 4530; Email: gardiner@manchester.ac.uk

${ }_{10}{ }^{b}$ School of Cancer and Enabling Sciences, University of Manchester UK. Fax: +44 (0)161 446 8565; Tel: +44 (0)161 446 3740; E-mail: Gordon.Jayson2@christie.nhs.uk

$\dagger$ Electronic Supplementary Information (ESI) available: $\left[{ }^{1} \mathrm{H},{ }^{13} \mathrm{C}\right.$ HMQC/HSQC, COSY data for new compounds, mass spectral data and 15 synthetic procedures for saccharides, PAGE analysis and biological assays]. See DOI: $10.1039 / \mathrm{b} 000000 \mathrm{x} /$

1. (a) B. Casu, A. Naggi and G. Torri, Matrix Biology, 2010, 29, 442452. (b) J. Bishop, M. Schuksz and J. D. Esko, Nature, 2007, 446, 1030-1037. (c) P. H. Seeberger and B. Werz, Nature, 2007, 446, 1046-1051. (d) F. Baleux, L. Loureiro-Morais, Y. Hersant, P. Clayette, F. Arenzana-Seisdedos, D. Bonnaffé and H. Lortat-Jacob, Nat. Chem. Biol., 2009, 5, 743-748.

2. (a) C. L. Cole, S. U. Hansen, M. Barath, G. Rushton, J. M. Gardiner, E.; Avizienyte and G. C. Jayson, PlosOne, 2010, 5, e11644. (b) C. Cole and G. C. Jayson, Expert Opin. Biol. Ther., 2008, 8, 351-362. (c) F. H. Blackhall, C. L. Merry and E. J. Davies, Brit. J. Cancer, 2001, 85, 1094-1098. (d) G. C. Jayson, M. Lyon and C. Paraskeva, J. Biol. Chem., 1998, 273, 51-57. (e) G. C. Jayson, C. Vives and C. 30 Paraskeva, Int. J. Cancer, 1999, 82, 298-304. (f) E. J. Davies, F. H. Blackhall and J. H. Shanks, Clin. Cancer Res., 2004, 10, 5178-5186. (g) A. C. Backen, C. L. Cole and S. C. Lau, Brit. J. Cancer, 2007, 96, 1544-1548. (h) M. K. Whitworth, A. C. Backen and A. R. Clamp, Clin. Cancer Res., 2005, 11, 4282-4288. (i) G. C. Jayson and J. T. Gallagher, Brit. J. Cancer, 1997, 75, 9-16. (j) J. Hasan, S. Shnyder, A. R. Clamp, A. T. McGown, R. Bicknell, M. Presta, M. Bibby, J. Double, S. Craig, D. Leeming, K. Stevenson, J. T. Gallagher and G. C. Jayson, Clin. Cancer Res., 2005, 22, 81728179 .

40 3. K. Dredge, E. Hammond, P. Handley, T. J. Gonda, M. T. Smith, C Vincent, R. Brandt, V. Ferro and I. Bytheway, Brit. J. Cancer, 2011, $1-8$.

4. (a) A. Lubineau, J-H. Lortat, O. Gavard, S. Sarrazin and D. Bonnaffé, Chem. Eur. J. 2004, 10, 4265-4282. (b) H. A. Orgueira, A. Bartolozzi, P. Schell, R. E. J. N. Litjens, E. R. Palmacci and P. H. Seeberger, Chem. Eur. J., 2003, 9, 140-169. (c) C. Noti, J. L. De Paz, L. Polito and P. H Seeberger, Chem. Eur. J., 2006, 12, 8664 8686. (d) J. L. De Paz, J. Angulo, J. M. Lassaletta, P. M. Nieto, MR. Horcajo, R. M. Lozano, G. G. Gallego and M. Martin-Lomas, ChemBioChem, 2001, 2, 673-685. (e) D. Bonnaffé, Comptes Rendus Chimie, 2011, 14, 59-73. (f) L. Poletti, M. Fleischer, C. Vogel, M. Guerrini, G. Torri and L. Lay, Eur. J. Org. Chem., 2001, 14, 2727-2734. (g) J. Paz, R. Ojeda, N. Reichardt and M. MartinLomas, Eur J. Org. Chem , 2003, 17, 3308-3324 (h) S-C. Hung, X-A. Lu, J-C. Lee, M. D-T. Chang, S-L. Fang, T-C. Fan, M. M. L. Zulueta and Y-Q. Zhong, Org. Biomol. Chem., 2012, 10, 760-772. (i) J.-C. Lee, X.-A. Lu, S. S. Kulkarni, Y.-S. Wen and S.-C. Hung, J. Am. Chem. Soc. 2004, 126, 476-477. (j) Y-P. Hu, S-Y. Lin, C-Y. Huang, M. M. L. Zulueta, J-Y. Liu, W. Chang and S-C. Hung, Nat.

60 Chem., 2011, 3, 557-563. (k) G. Tiruchinapally, Z. Yin, M. ElDakdouki, X. Wang and X. Huang, Chem. Eur. J., 2011, 17, 1010610112. (1) M. M. L. Zulueta, S.-Y. Lin, Y.-T. Lin, C.-J. Huang, C.C. Wang, C.-C. Ku, Z. Shi, C.-L. D. Chyan, L.-H. Irene, T.-I. Lim, Y.-P. Tsai, S. D. Hu, C.-H. Wong and Hung, S.-C. J. Am. Chem. Soc., 2012, 134, 8988-8995. (1) S. Arungundram, K. Al-Mafraji, J. Asong, F. E. Leach, I. J. Amster, A. Venot, J. E. Turnbull and G.-J. Boons, J. Am. Chem. Soc., 2009, 131, 17394-17405. (m) J. L. De Paz, C. Noti, and P. H. Seeberger, J. Am. Chem. Soc., 2006, 128 , 2766-2767. (n) J. L. De Paz. and M.-M. Lomas, Eur. J. Org.,
5. The nomenclature derived by Esko et al for the disaccharide structure code of GAGs has been used accordingly: R. Lawrence, $\mathrm{H}$ Lu, R. D. Rosenberg, J. D. Esko and L. Zhang, Nat. Methods, 2008, 5, 291-292.

756 Y. Xu, S. Masuko, M. Takieddin, H. Xu, R. Liu, J. Jing, S. A Mousa, R. J. Linhardt, and J. Liu, Science, 2011, 334, 498-501.

7. T. Polat, and C.-H. Wong, J. Am. Chem. Soc., 2007, 129, 12795 T. Polat,
12800.

8. (a) (i) S. U. Hansen G. J. Miller, M. Baráth, K. R. Broberg, E. Avizienyte, G. C. Jayson, and J. M. Gardiner, J. Org. Chem., 2012 77, 7823-7843 (ii) S. U. Hansen, G. J. Miller, G. C. Jayson and J. M. Gardiner, Org. Lett., 2013, 15, 88-91. (b) S. U. Hansen, M. Baráth, B. A. B. Salameh, R. G. Pritchard, W. T. Stimpson, J. M Gardiner and G. C. Jayson, Org. Lett., 2009, 11, 4528-4531. (c) Available in 9 steps and $12 \%$ overall yield from $D$-glucosamine as per ref $8 \mathrm{a}$.

9. For $\boldsymbol{\alpha}-\mathbf{6}$ (prepared in 10 steps from diacetone-D-glucose): $\mathrm{N}$. Barroca and J. C. Jacquinet, Carbohydr. Res., 2000, 329, 667-679. For 及-6: L. Rochepeau-Jobron and J. C. Jacquinet, Carbohydr. Res., 1997, 303, 395-40.

10. S. Maza, J. L. de Paz, P. M. Nieto, Tetrahedron Letters, 2011, 52, 441-443.

11. W. Chai, J. Luo and A. M. Lawson, Anal. Chem., 1998, 70, 20602066.

95 12. N. C. Smits, S. Kurup, A. L. Rops, G. B. ten Dam, L. F. Massuger, T. Hafmans, J. E. Turnbull, D. Spillmann, J. P. Li, S. J. Kennel, J. S. Wall, N. W. Shworak, P. N. Dekhuijzen, J. van der Vlag and T. H. van Kuppevelt, J. Biol. Chem., 2010, 52, 41143-41151. 